\title{
Impact of Ministry of Health Interventions on Private Medicine Retailer Knowledge and Practices on Anti-Malarial Treatment in Kenya
}

\author{
Timothy Abuya,* Greg Fegan, Yvone Rowa, Baya Karisa, Sam Ochola, \\ Wilfred Mutemi, and Vicki Marsh \\ Kenya Medical Research Institute/Wellcome Trust Centre for Geographic Medicine Research-Coast, Kilifi, Kenya; Infectious \\ Disease Epidemiology Unit, Department of Epidemiology and Population Health, London School of Hygiene and \\ Tropical Medicine, London, United Kingdom; Ministry of Health, Kilifi District Hospital, Kilifi, Kenya; Provincial \\ Medical Officer, Nairobi Province, Kenya; World Vision Kenya, Nairobi, Kenya; Centre for Clinical Vaccinology and \\ Tropical Medicine (CCVTM), University of Oxford, Headington, Oxford, United Kingdom
}

\begin{abstract}
Small-scale interventions on training medicine retailers on malaria treatment improve over-the-counter medicine use, but there is little evidence on effectiveness when scaled up. This study evaluated the impact of Ministry of Health $(\mathrm{MoH})$ training programs on the knowledge and practices of medicine retailers in three districts in Kenya. A cluster randomized trial was planned across 10 administrative divisions. Findings indicated that $30.7 \%$ (95\% confidence interval $[\mathrm{CI}]: 23.3,39.0)$ and $5.2 \%(95 \% \mathrm{CI}: 2.1,10.3)$ of program and control retailers, respectively, sold MoH amodiaquine with correct advice on use to surrogate clients (OR $=8.8 ; 95 \%$ CI: 2.9, 26.9; $P<0.001)$. Similarly, 61.8\% (95\% CI: 54.2, $69.1)$ and $6.3 \%(95 \% \mathrm{CI}: 2.7,12.1)$ of program and control retailers, respectively, reported correct knowledge on dosing with amodiaquine $(\mathrm{OR}=29.8 ; 95 \% \mathrm{CI}: 8.2,108.8)$. Large-scale retailer training programs within the national malaria control framework led to significant improvements in retailers' practices across three districts.
\end{abstract}

\section{INTRODUCTION}

Effective interventions against malaria are available, yet the burden of malaria persists in many parts of sub-Saharan Africa (SSA). ${ }^{1}$ Many of the most effective interventions are based on preventive strategies, particularly the use of insecticide-treated bed nets (ITNs), with recent evidence of the intervention reaching the most poor in some settings. ${ }^{2,3}$ Other strategies have addressed ways of improving access to effective treatment, given that populations at risk are often unaware of existing interventions or unable to access or afford them. ${ }^{1} \mathrm{~A}$ series of interventions to improve home access to treatment have been suggested, described, and tested in recent years, ${ }^{4-10}$ leading to the development of a global strategy for home management of malaria (HMM). ${ }^{11}$

The rationale for the HMM strategy is based on two main documented premises: self-treatment is common and often inappropriate, ${ }^{12-18}$ and, although reliance on fever alone may lead to over diagnosis, ${ }^{19-21}$ it remains the key trigger for prompt and effective presumptive treatment of uncomplicated malaria and can prevent evolution to severe malaria, reduce malarial anemia, and death. ${ }^{22-24}$ HMM interventions are based on research and operational evidence and experience. ${ }^{5-7,25-27}$ They include improving adherence to medication through unit dose pre-packing; increasing drug availability; educating community members; increasing provider knowledge through training community level providers, including private medicine retailers (PMR); and strengthening public health systems. ${ }^{11}$ $\mathrm{HMM}$ is included as part of the national malaria strategies of 22 African countries. ${ }^{28}$

The 2001 Kenya National Malaria Strategy (KNMS) included HMM and specifically promoted programs to strengthen PMR practices and community use of over-the-counter (OTC) antimalarial (AM) medicines. In 2002, the Division of Malaria Control (DoMC) in the Ministry of Health $(\mathrm{MoH})$ adopted

*Address correspondence to Timothy Abuya, Kenya Medical Research Institute/Wellcome Trust Centre for Geographic Medicine Research-Coast, 80108, PO Box 230, Kilifi, Kenya. E-mail: Tabuya@ kilifi.kemri-wellcome.org a policy to implement PMR training programs in malariaendemic districts in Kenya, ${ }^{29}$ beginning with five district "demonstration" programs. This study presents findings from an evaluation of PMR programs in three of these districts: Kwale, Busia, and Makueni. This paper describes the findings of quantitative surveys to assess the impact of these $\mathrm{MoH}$ programs on PMR knowledge and practices using a cluster randomized controlled trial. Findings from qualitative component of this evaluation will be described separately.

Makueni and Kwale districts are sentinel districts for national malaria monitoring and evaluation activities and represent different malaria ecologies. ${ }^{30,31}$ Kwale district experiences seasonal high-intensity coastal malaria transmission, whereas Makueni is a semi-arid district with acute seasonal low transmission. ${ }^{32}$ Although Busia district is not a sentinel site, it was included in this evaluation to represent an area of perennial high-intensity malaria transmission around the lake region. ${ }^{33}$ Details of the geography of the districts have been described previously. ${ }^{34}$

Following the DoMC guidelines, all three districts aimed to implement programs with two core components: workshop based training of all PMRs selling AM medicines and widespread public information campaigns on the use of OTC AMs. The intervention used the existing structure of the retail sector and did not interfere with the existing AM distribution chain. The DoMC allocated program funds from the Global Fund to fight AIDS, tuberculosis (TB), and malaria (GFATM) after review of work plans developed by each District Health Management Team (DHMT). Funds were disbursed through the DoMC on a quarterly basis on submission of DHMT reports; in total, US\$5202 and US\$5882 were released to Kwale and Makueni, respectively, for the implementation of the programs in the setup year. The program evaluated in Busia was implemented with funds from the United Nations Children's Fund (UNICEF), with a total of US\$5838 allocated to train two divisions.

A core team of trainers was identified by the DHMT and trained in central workshops with technical support from research groups experienced in PMR programs. The training of trainers' workshop was followed by technical supervision of one or two PMR workshops in each district to support the 
development of teaching skills. Centrally produced information education and communication (IEC) materials included information booklets for PMRs to support training activities and posters to identify program outlets. Five hundred booklets and posters were delivered to Makueni district, and 200 and 100 of each of these materials were sent to Kwale and Busia districts, respectively. Districts were provided with templates to produce their own core program reference materials on AM drug use and situations where a sick child should be seen by a trained health worker. Kwale, Busia, and Makueni produced 60,100 , and 300 of these charts, respectively. The districts received bicycles to support local monitoring and public information. The implementing team was made up of the divisional public health officers (officers in charge of public health activities and sanitation in the local areas), undertaking the main management and training roles, and locally trained community resource persons who supported local coordination of training and public information campaigns.

The PMR programs were developed and implemented during a transition of the national drug policy from sulphadoxine/sulphalene-pyrimethamine medicines (SP) as the first-line recommended AM treatment to artemisinin-based combination therapies (ACTs). ACTs were, and remain, registered as prescription-only medicines (POM) recommended for formal sector providers, pending further experience with the new policy. ${ }^{35,36}$ In view of the failure rates for SP drugs in many parts of Kenya, the DoMC identified amodiaquine (AQ) as the most appropriate OTC AM medicine at the time of the training. ${ }^{35}$ Indicators for the evaluation were designed around use of AQ and SP medicines, with primary indicators concerning AQ use. The change in drug policy led to delays in implementing the PMR programs in Kwale and Makueni. In Busia, training on SP medicines was implemented in the intervention division before the drug policy change. In this district, there was strong donor interest in PMR training leading to the subsequent widespread DHMT implementation of AQ-based PMR programs, using donor funds from various sources by UNICEF using the DoMC model.

Training in each district began by selecting and recruiting PMRs in the program areas (Figure 1). In Kwale, Busia, and Makueni, 122, 79, and 247 PMRs, respectively, were reportedly trained in intervention divisions. In these settings, the number of outlets per division varies between 300 and 400 retail outlets. Recruitment targeted the main sellers in outlets stocking AM medicines that were located in rural settings and described as relatively stable on the basis of local knowledge. Trainers and co-trainers trained PMRs in 2-day workshops at local venues. The training covered signs of simple and severe malaria; malaria treatment and prevention; drug resistance; referral practices; storage and expiry of medicines; and communication skills. Public information activities were based on local public meetings and use of posters outside trained outlets and in public places.

\section{MATERIALS AND METHODS}

Study areas and design. The study was designed and planned as a cluster randomized trial across three districts with divisions (the fourth administrative tier in Kenya with an average population of between 50,000 and 100,000 people) as the units of randomization. The DHMTs in each district identified divisions they considered similar in socioeconomic characteristics, malaria burden, malaria control programs, and access to health care facilities before randomization. In Kwale and Makueni, two interventions and two controls divisions were selected. In Busia, as described under the section on program implementation, the national drug policy change prevented use of the original divisions randomly chosen for the evaluation. In this district, one intervention and one control division were purposively selected after intervention by the DHMT. The replacement intervention area was a division in which the DHMT had implemented an AQ-based PMR program using the DoMC model with UNICEF funds. The replacement control division was selected to provide a comparable setting in relation to the selection criteria described above. Across all three districts, there were five intervention clusters and five clusters that acted as controls. The evaluation was conducted between July and October 2005: an average of 6 months for Kwale and Makueni programs and 8 months for the Busia program after completion of the last training workshop.

The sample size calculation for the study was based on the primary indicator: the proportion of program outlets where recommended AM medicines were sold accompanied by adequate advice on their use. The study was powered to show a $20 \%$ difference between control and intervention outlets within districts with an estimated $5 \%$ of outlets selling AM medicines adequately before the intervention. Because the number of sales required (60) was close to the total number of PMRs trained per division, all trained outlets in the divisions, identified from district quarterly reports, were included in the study. In control areas, 80 outlets were randomly selected from a sampling frame of all outlets selling AM medicines developed with information from public health officers and local chiefs.

Surrogate client survey. Surrogate client surveys (SCSs) are a method in which a fieldworker poses as a client seeking care from a provider who is unaware of their identity. The researcher provides the fieldworker with a standardized scenario to present to the selected providers. ${ }^{37,38}$ The survey was conducted to assess the impact on retailer practices attributable to the program. The survey collected information on the behavior of retailers while selling OTC AM medicines. Six female field workers per division were trained and visited outlets away from their own homes to avoid recognition. They used a standardized scenario, which entailed asking for an AM medicine for a child. If asked, they provided standardized information on the child and the illness, including an age of 3 years. Details of the transaction, including the drugs bought, advice on dose, and questions asked, were entered on a simple checklist shortly after the transaction and away from the outlet.

Retail audit. Retail audits (RAs) were used to collect information on general characteristics of the outlets and retailers, AM medicines stocked, price of AM available, and retailers' knowledge on the treatment of childhood fevers. Knowledge was tested using a vignette to determine the advice that PMRs would give on the management of a simple fever (without difficulty in breathing or diarrhea or vomiting more than three times a day or fits) in a 5-year-old child, including the dosages of AQ and/or SP medicines stocked in their outlets. Before each interview, field workers gave an explanation of the purpose of the survey. A pre-tested semi-structured questionnaire was used to collect the information.

Data analysis. Assessment of adequateness of advice of AM medicines was based on compatibility with national malaria guidelines for which 200-mg AQ tablets is administered 




FIGURE 1. Map showing the geographic location of study districts and intervention and control areas in each study district.

for 3 days to give a total of $200-450 \mathrm{mg}$ for a full course for a child $<5$ years of age. For syrups, a $50-\mathrm{mg} / 5-\mathrm{mL}$ AQ base is administered for the same period with $<5$ years of age dosage being 7-10 teaspoonfuls. Data was double entered using FoxPro Version 6 software (Microsoft, Redmond, WA). Verification, data cleaning, and analysis were conducted using STATA version 8 (Stata, College Station, TX). Preliminary analyses of associations were conducted in STATA followed by the fitting of multi-level logistic regression analysis using generalized linear latent and mixed models (GLLAMM). ${ }^{39}$ The study was approved by the Kenya National Scientific Steering and Ethical Research Committees and the World Health Organization Secretariat Committee on Research Involving Human Subjects (WHO SCRIHS). The aims and purpose of all components of the study were discussed and agreed with local leaders. Verbal informed consent was sought for the retail audit. Given the nature of the method, informed consent could not be sought from PMRs for the SCS. Consent was obtained from community leaders, and permission for an individual informed consent waiver was granted by the ethical committees.

\section{RESULTS}

Characteristics of outlets and PMRs. The characteristics of retail outlets visited are presented in Table 1. Generally, in the Kenyan context, general shops vary in size and sell general household goods alongside OTC medicines such as AM, painkillers, and cough syrups. They are not allowed to sell prescription-only medicines. Although drug shops are ideally licensed to sell all categories of medicines, most of them are not manned by professional pharmacists at all times. In the study sites, a total of 307 and 309 trained outlets were visited across all the clusters during the SCS and RA, respectively. During the surveys, the number of functioning trained outlets on the ground was less than those recorded as trained in all districts. In Kwale, $24 \%$ of trainees had changed business or had closed their outlets. In Makueni and Busia, 4\% and 5\%, respectively, of trainees had closed their outlets within 6-8 months after training.

The study was designed to determine the overall impact of $\mathrm{MoH}$ programs on PMR knowledge and practices. Important differences in the measured impacts emerged between these three districts and are presented alongside pooled analysis. There were no differences between outlets in intervention and control areas in the proportion of PMRs that stocked AM medicines $(P=0.451)$ across all sites. However, there were variations on this indicator in Makueni and Kwale districts (Table 1). There were also no differences in the characteristics of PMRs such as sex, age, and levels of education or type of outlets. Most outlets were manned by one seller, $<35$ years of age (mean age, 33.4 and 31.9 years in the intervention and control, respectively) and with $\sim 9$ years of schooling (mean years in school, 9.6 and 9.2 in the intervention and control areas, respectively). A higher proportion of intervention outlets had 
more than one seller working at the same time (25.1\% versus $9.6 \% ; P=0.056)$. District level analysis indicated significant differences on this characteristic in Makueni district (Table 1). Of all outlets with an AM medicine, $88.8 \%$ and $73.5 \%$ of intervention and control outlets, respectively, stocked AQ medicines $(P=0.948)$.

Retailer selling practices for AM medicines. Data on retailer practices were derived from the SCS. Table 2 presents data on the frequency with which retailers sought to identify the age of the user or the nature of illness before selling medicines. Across all the districts, intervention PMRs more commonly asked questions about the age of user (odds ration [OR] = 2.1; $95 \%$ CI: $1.3,3.4 ; P=0.002)$, duration of the illness (OR = $6.7 ; 95 \% \mathrm{CI}: 2.3,19.5 ; P<0.001)$, and any previous treatment $(\mathrm{OR}=7.5 ; 95 \% \mathrm{CI}: 2.2,26.7 ; P=0.002)$. District level analysis indicate that, for all the parameters measured on the ability to identify the age and nature of illness, intervention PMRs did better than controls ones in Makueni district.

Table 3 shows the types of medicines sold and the advice given on dosage. Overall, 30.7\% (95\% CI: 23.3, 39.0) of all medicine sales through intervention PMRs and 5.2\% (95\% CI: 2.1, 10.3) of these through control PMRs included the $\mathrm{MoH}$-recommended $\mathrm{AM}$ with correct advice on its use $(\mathrm{OR}=$ 8.8; 95\% CI: 2.9, 26.9; $P<0.001)$. As shown in Table 3, surrogate clients were sometimes sold antipyretic drugs after asking for an AM, with $20.9 \%$ of intervention and $41.5 \%$ of control PMRs selling an antipyretic on its own (OR $=0.3$; 95\% CI: $0.2,0.6 ; P=0.002)$. Among those that were sold any medicine, a higher proportion $(52.4 \%)$ of intervention than control $(21.5 \%)$ PMRs sold AQ medicines (OR = 5.0; 95\% CI: 2.0, 12.3; $P<0.001)$ and gave appropriate advice on their use $(\mathrm{OR}=$ 4.9; $95 \%$ CI: $1.7,13.8 ; P=0.003)$.

District level analysis indicated that Makueni experienced the greatest differences between intervention and control PMRs for almost all the measured outcomes, as shown in Table 3. In Busia, a relatively high proportion of control PMRs sold AQ with correct advice on its use to surrogate clients, and no significant differences emerged between these and intervention areas for this outcome. In Kwale, substantially more program than control area PMRs sold AQs to surrogate clients, but these differences were not statistically significant for the proportion providing correct advice on AQ use.

Retailer's knowledge on treating childhood fever. Private medicine retailer's knowledge on treating childhood fevers and dosages of AQ and SP medicines was assessed in the RA; the findings are summarized in Table 4. A higher proportion of intervention than control PMRs recommended an AM medicine $(\mathrm{OR}=5.7 ; 95 \% \mathrm{CI}: 2.9,11.3 ; P<0.001)$, and this difference was more marked for knowledge of the correct dosage for AQ medicines $(\mathrm{OR}=29.8$; $95 \% \mathrm{CI}$ : 8.2, 108.8; $P<0.001)$, including less often recommending single-dose treatment of AQ $(\mathrm{OR}=0.02$; 95\% CI: 0.005, 0.16; $P<0.001)$. Retailers' knowledge on dosing of SP medicines showed no statistically significant differences between the control and intervention areas. District level differences for these indicators show that there were differences between trained and control PMR's knowledge on fever treatment and use of AQ in all districts. However, in Kwale and Makueni, intervention PMRs more commonly gave incorrect advice on SP dosages than control PMRs, with $47.8 \%$ and $50.0 \%$ in these districts, respectively, describing use of SP drugs over a 3-day period instead of the recommended single dose. 


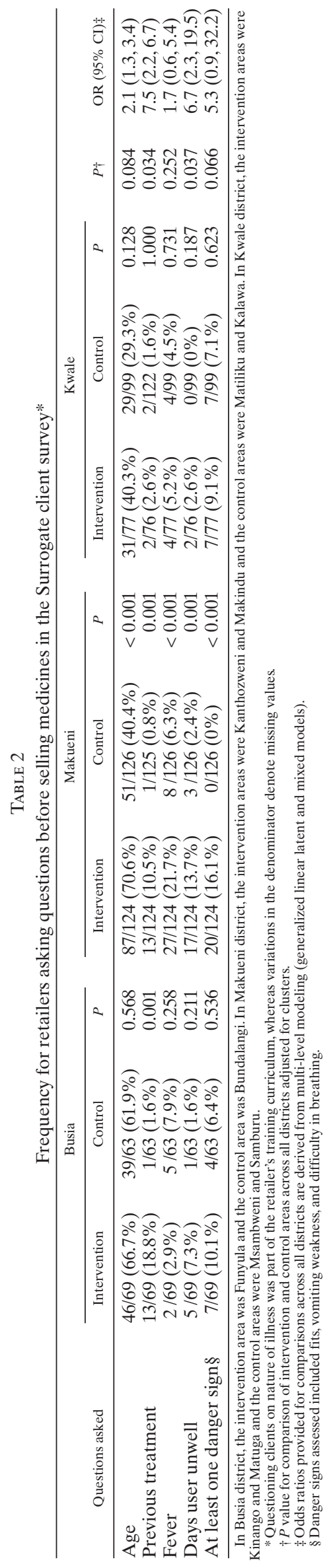

Price of SP and AQ medicines in the retail outlets. Data on price of AM medicines were derived from all outlets that stocked AM medicines during the RA. Retail and wholesale purchase prices are presented for adult treatment regimens based on national dosage guidelines. Across all districts, the median wholesale purchase price for AQ medicines at source was US\$0.48 (IQR: 0.42-0.60; USD derived based on Central Bank of Kenya exchange rates http:/www.centralbank.go.ke/ rates/exchangeindex.asp), with a retail price of US\$0.90 (Interquartile range [IQR]: 0.67-0.90). The median wholesale purchase price for SP medicines was US\$0.18 (IQR: 0.15-0.25), retailing at US\$0.30 (IQR: 0.30-0.37). The price mark-up for full adult courses for AQ and SP were, therefore, US\$0.42 and US\$0.22, respectively.

\section{DISCUSSION}

The MoH programs evaluated in this study aimed to improve home management of presumptive childhood malaria through training PMRs and creating greater community awareness concerning the use of OTC AM medicines. ${ }^{29}$ Earlier studies evaluating PMR interventions in malaria control have primarily assessed small-scale and site-specific programs. ${ }^{5,7,25,27,40}$ This study, by using a randomized controlled approach to evaluating relatively large-scale $\mathrm{MoH}$ programs in three districts, aims to contribute to national and international policy debates on the value and feasibility of working with PMRs within the framework of national malaria control programs. Overall, the $\mathrm{MoH}$ programs led to a major improvement in PMR practices with a significantly higher proportion of intervention PMRs stocking AQ medicines, asking questions about the age, duration of illnesses, previous treatment, and selling AQ with accurate information on its use. There was also an impact on PMR knowledge with intervention PMRs being more likely to know how to use AQ medicines than those from control areas.

In interpreting the findings of this study, it is important to take into account potential methodologic limitations. These include the survey methods, the loss of randomization in Busia, reduced power for within-district analyses, and the time frame for the evaluation. To limit potential bias associated with the SCS method, the surrogate clients were recruited locally, visited outlets outside their normal location, and were trained using a skills based approach, but close supervision was not possible given the covert nature of the method.

The study was designed as a cluster randomized trial, a methodologically rigorous approach to evaluating community level interventions. ${ }^{41-43}$ In this study, the protracted process of changing the national AM drug policy led to the necessary purposive selection of intervention and control areas in Busia district. The selection criteria for these divisions aimed to ensure comparability with each other and other sites. Surrogate client study findings point to smaller and not statistically significant differences between intervention and control areas in Busia, with higher levels of appropriate behavior in control areas than in the other two districts. It is possible that there had been some degree of contamination in Busia, a suggestion supported by the DHMT's report that the district had experienced almost complete coverage with PMR programs at the time of the evaluation, leaving only one division as the control.Any such effect would reduce the measured impact of the programs. The district level analysis also points to a perverse outcome of the programs in Kwale and Makueni, where there was increased inappropriate advice on the use of SP medicines 


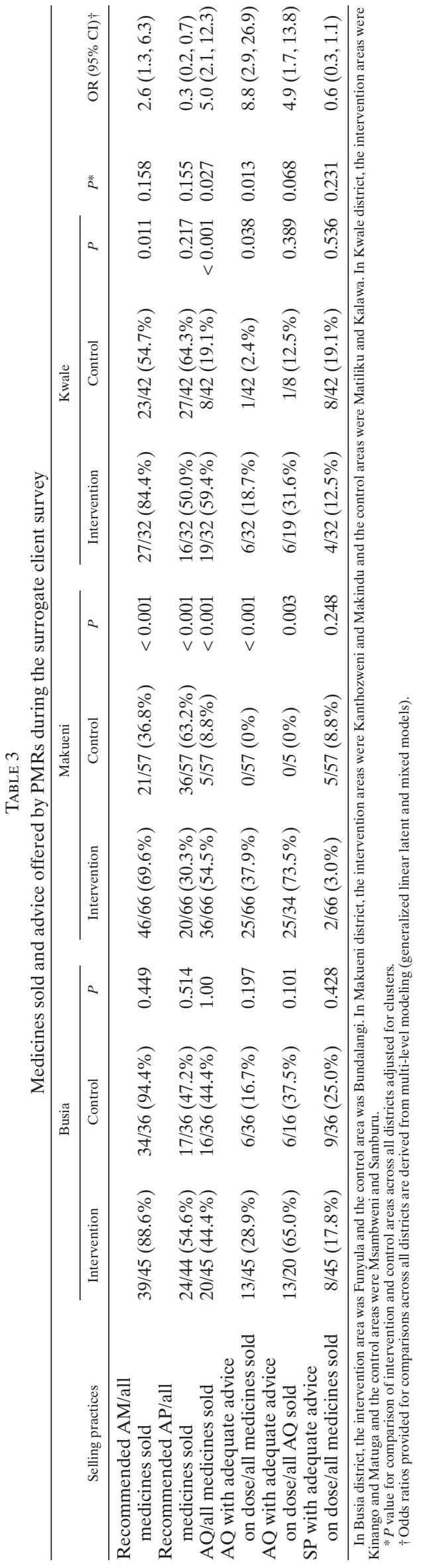

in program compared with control outlets. The pattern of this advice strongly suggests that PMRs had difficulty in distinguishing between different types of AM, and strategies to simplify recognition such as pre-packaging, overbranding, and mass media IEC campaigns may be an important part of PMR training programs.

Although the choice of study sites was based on specific criteria that attempted to match the intervention with the control areas, results for within-district analysis should be interpreted with caution. This is largely because of the small number of clusters for each site and the potential non-comparability linked to other unknown potential confounders not taken into account. However, a comparison of the characteristics of PMRs and their outlets in intervention and control areas suggests that the randomization process was generally effective. There were no marked differences in the educational status or age between intervention and control PMRs. The only major difference was that intervention outlets more often had more than two PMRs working at the same time. However, this situation applied to few outlets, because a majority of outlets $(>75 \%)$ across all areas were manned by one retailer. It is, however, possible that having more than one retailer at a time may be associated with larger more commercially stable businesses. ${ }^{44}$ Our findings on educational status of PMRs concurs with other reports in the literature that show variations in levels of education. . $^{7,25,45-47}$ The study outlets are likely to reflect the type of outlets common in rural settings of SSA. ${ }^{45,46,48,49}$

Another caveat in interpreting the results within districts relates to the number of AM sales needed to power the study adequately. The number of AM sales was adequate for the primary indicator across districts but fell below that needed for within-district comparisons as a result of low numbers of trained outlets in some districts and very low measures for key indicators, particularly in control areas. In Kwale in particular, the small number of program and control outlets recommending AQ made the detection of any differences difficult to show. Two final limitations concern the timing of this survey and the absence of data on community OTC drug use. It is likely that any impact of training on PMR practices would be seen within a relatively short period of time. However, long-term program impacts and any resulting changes in community drug use remain to be explored.

In addition to the specific challenges that have been recognized for interventions with PMRs, ${ }^{9}$ issues that are more generally raised concern the feasibility and sustainability of implementing innovative programs through the $\mathrm{MoH}$, given the constraints of bureaucracy and resource limitations that characterize many government departments. ${ }^{50} \mathrm{~A}$ cost-effectiveness study of a PMR program in Kenya suggested that, although the initial cost of setting such programs is high, the annual running costs could be contained within a typical district budget. ${ }^{51}$ In this respect, it is salient to note that the impacts reported here occurred despite any such challenges and with relatively low total budget allocations for implementation. Two issues emerged from the current quantitative assessments that reflect on implementation issues. First, between $4 \%$ and $24 \%$ of trained outlets closed within 6-8 months of training. The dynamic nature of the private retail sector creates challenges in planning interventions, because PMRs in many parts of SSA enter and exit the market depending on their immediate financial situation. ${ }^{5,9}$ Although a more stable retail market has also been described elsewhere ${ }^{40}$ this fluidity in the retail sector 


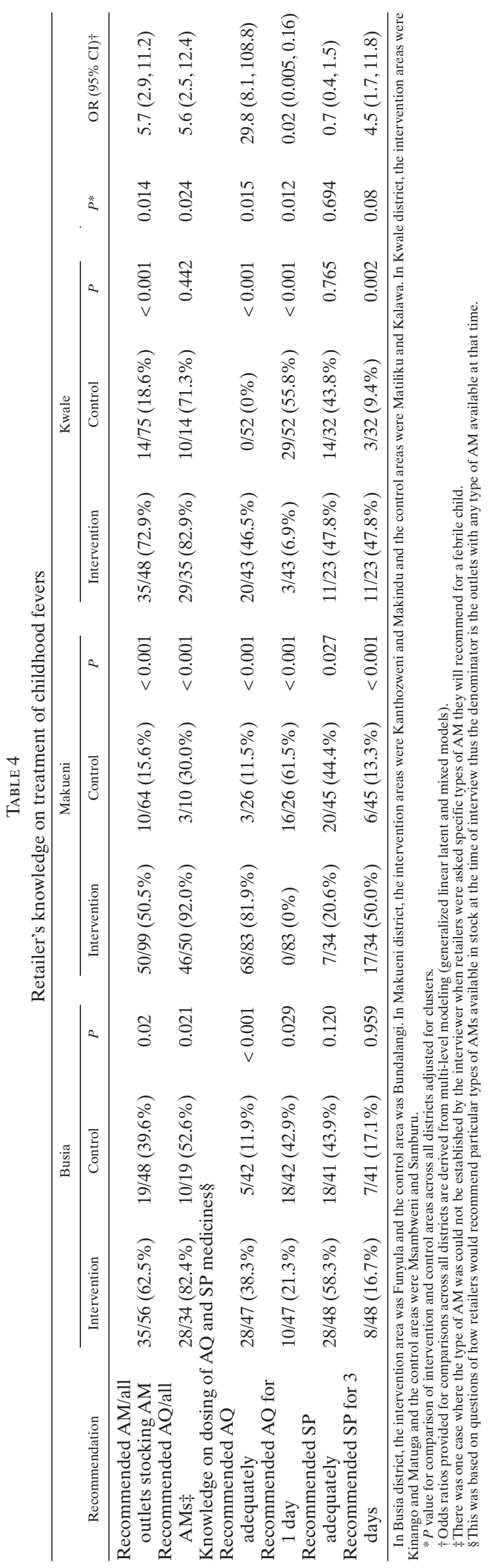

in Kenya has implications for the sustainability and impact of interventions targeting PMRs. Second, there were differences in the number of PMRs trained between districts, with Makueni training higher numbers of PMRs compared with the other sites. District level analyses also show that the greatest impacts were seen in Makueni, suggesting that the potential benefits of such programs may be much higher if the implementation issues of the district health systems are addressed. Such issues will be thoroughly addressed in the qualitative study to be reported later. However, the sustainability of knowledge gained is still unknown for such programs.

A potentially positive factor supporting implementation at the provider level was the increased price mark-ups derived from sales of AQ medicines in comparison to SP. The prices of a full adult course of AQ and SP medicine in the study sites represent retail mark ups of $114 \%$ and $66 \%$, respectively, which compares well with another study conducted in Kenya. ${ }^{44}$ Retailers may therefore be encouraged to support implementation of the new AQ drug policy, leading to increased supply. This would only have an effect on community level drug use if AQ medicines were affordable to clients. Retailers rarely realize huge profits because of the interplay of many factors including perceived high costs of a full dose, client attitudes, and broader market forces. ${ }^{44,49}$ The cost of treating malaria is likely to continue increasing as more effective first-line AM medicines are introduced in the essential drug list of SSA countries. Although pediatric prices may be a third of the adult prices, adults tend to consume large amounts of AM medicines, ${ }^{34}$ with huge implications on household budgets that ultimately bear the largest cost of treating malaria. ${ }^{52}$

This study points to important and current policy issues around the introduction of ACTs. The transition to ACT medicines as a first-line drug for malaria treatment poses many challenges to malaria control activities ${ }^{53}$ and particularly the implementation of PMR programs. The introduction of ACTs for retail sector interventions is likely to suffer from legal delays because ACTs are still a prescription-only medicine in many countries. In addition, compared with previous OTC AM medicines, the high cost of ACTs is likely to limit access to treatment to communities in need. However, subsidized ACTs are being distributed through PMRs under the current pilot programs of global subsidies-Affordable Medicines-Facility Malaria in $\sim 12$ countries in SSA (including Kenya) and Asia. Although use of ACTs for the retail sector is likely to change the nature of interventions required increasing its complexity, these findings are relevant because they show that changes in knowledge and behavior of PMRs can be achieved even in the context of multi-dose regimens such as AQ. Finally, bringing together issues of the increasing cost of treating malaria, the potential for the development of parasite resistance in settings where indiscriminate use of AM is widespread, the difficulties in diagnosis, ${ }^{10,54}$ and the tendency for low-risk adults to use more OTC AMs than high-risk children, ${ }^{34}$ this study questions the appropriateness of presumptive treatment of fevers especially in settings with low malaria transmission such as Makueni district. This observation supports the need to study the use of diagnostics such as dipsticks for HMM to improve effectiveness of using ACTs. ${ }^{55}$

Relatively large-scale $\mathrm{MoH}$ malaria control programs targeting PMRs in Kenya led to important improvements in PMR knowledge and practices. The implementation process of such programs is likely to have influenced differences between 
districts, and there is a need to understand and address these to strengthen program impacts. Long-term evaluations of the impact of PMR programs on retailer practices and community drug use are important future areas of research. As the evidence around approaches using subsidized OTC AM medicines is sought, this study clearly showed that district health initiatives based on short PMR trainings and traditional public information campaigns with simple IEC materials improve provider performance and have the potential to improve child survival in malaria-endemic settings.

Received November 17, 2008. Accepted for publication February 5, 2009.

Acknowledgments: We are grateful to all study subjects, the support and contributions of the District Health Management Teams, administrative leaders, field workers, and community members in Busia, Kwale, and Makueni districts. We also thank Richard Rimba and Francis Kombe for providing logistical support during data collection and Bob Snow, Catherine Goodman, and Kara Hanson for comments on earlier versions of the manuscript.

Financial support: This study was supported by WHO/TDR, CDC, the Kenya Medical Research Institute (KEMRI), and the Wellcome Trust. This paper is published with the permission of the Director of KEMRI.

Authors' addresses:Timothy Abuya,Kenya Medical Research Institute/ Wellcome Trust Centre for Geographic Medicine Research-Coast, 80108, PO Box 230, Kilifi, Kenya, Tel: 254-41-7522063/254-41-7525044, Fax: 254-41-7522390, E-mail: Tabuya@kilifi.kemri-wellcome.org. Greg Fegan, Kenya Medical Research Institute/Wellcome Trust Centre for Geographic Medicine Research-Coast,80108,POBox230,Kilifi,Kenya, Tel: 254-41-7522063/254-41-7525044, Fax: 254-41-7522390, E-mail: gfegan@kilifi.kemri-wellcome.org and Infectious Disease Epidemiology Unit,Department of Epidemiology and Population Health,London School of Hygiene and Tropical Medicine, Keppel Street, London WC1E 7HT, UK. Yvone Rowa, Kenya Medical Research Institute/ Wellcome Trust Centre for Geographic Medicine Research-Coast, 80108, PO Box 230, Kilifi, Kenya, Tel: 254-41-7522063/254-41-7525044, Fax: 254-41-7522390, E-mail: Yverowa@yahoo.co.uk. Baya Karisa, Ministry of Health, Kilifi District Hospital, 80108, PO Box 9, Kilifi, Kenya, Tel: 254-41-522777, E-mail: ekbaya@yahoo.co.uk. Sam Ochola, Provincial Medical Officer, PO Box 34349-00100, Nairobi Province, Nairobi, Tel: 254-20-217129/20-313481, Fax: 254-20-217129, E-mail: Sochola06@yahoo.com. Wilfred Mutemi, World Vision Kenya, E-mail: wilfred_mutemi@wvi.org. Vicki Marsh, Kenya Medical Research Institute/Wellcome Trust Centre for Geographic Medicine ResearchCoast, 80108, PO Box 230, Kilifi, Kenya, Tel: 254-41-7522063/254-417525044, Fax: 254-41-7522390, E-mail: vmarsh@kilifi.kemri-wellcome .org and Centre for Clinical Vaccinology and Tropical Medicine, University of Oxford, Headington, Oxford OX3 9DU, UK.

\section{REFERENCES}

1. Were W, 2004. Bringing Malaria Management closer to the Home. Geneva: Roll Back Malaria Department, World Health Organisation.

2. Lengeler C, 2004. Insecticide-treated bed nets and curtains for preventing malaria. Cochrane Database Syst Rev CD000363.

3. Noor AM, Amin AA, Akhwale WS, Snow RW, 2007. Increasing coverage and decreasing inequity in insecticide-treated bed net use among rural Kenyan children. PLoS Med 4: e255.

4. Hetzel MW, Dillip A, Lengeler C, Obrist B, Msechu JJ, Makemba AM, Mshana C, Schulze A, Mshinda H, 2008. Malaria treatment in the retail sector: knowledge and practices of drug sellers in rural Tanzania. BMC Public Health 8: 157.

5. Marsh VM, Mutemi WM, Willetts A, Bayah K, Were S, Ross A, Marsh K, 2004. Improving malaria home treatment by training drug retailers in rural Kenya. Trop Med Int Health 9: 451-460.

6. Brieger WR, Unwin A, Greer G, Meek S, 2004. Interventions to Improve the Role of Informal Private Providers in Malaria Case
Management for Children in Africa. BASICS II and the Malaria Consortium. Prepared for The Malaria Case Management Working Group, Roll Back Malaria.

7. Tavrow P, Shabahang J, Makama S, 2003. Vendor-to-vendor education to improve malaria treatment by private drug outlets in Bungoma District, Kenya. Malar J 2: 10.

8. Kidane G, Morrow RH, 2000. Teaching mothers to provide home treatment of malaria in Tigray, Ethiopia: a randomised trial. Lancet 356: 550-555.

9. Goodman CBW, Unwin A, Mills A, Meek S, Greer G, 2007. Medicine sellers and malaria treatment in Sub-Saharan Africa: what do they do and how can their practice be improved? Am J Trop Med Hyg 77: 203-218.

10. Hetzel MW, Iteba N, Makemba A, Mshana C, Lengeler C, Obrist B, Schulze A, Nathan R, Dillip A, Alba S, Mayumana I, Khatib RA, Njau JD, Mshinda H, 2007. Understanding and improving access to prompt and effective malaria treatment and care in rural Tanzania: the ACCESS Programme. Malar J 6: 83.

11. World Health Organization, 2004. Scaling Up Home Management of Malaria: From Research to Implementation. Geneva: World Health Organisation.

12. Holtz TH, Kachur SP, Marum LH, Mkandala C, Chizani N, Roberts JM, Macheso A, Parise ME, 2003. Care seeking behaviour and treatment of febrile illness in children aged less than five years: a household survey in Blantyre District, Malawi. Trans $R$ Soc Trop Med Hyg 97: 491-497.

13. Deming MS, Gayibor A, Murphy K, Jones TS, Karsa T, 1989. Home treatment of febrile children with antimalarial drugs in Togo. Bull World Health Organ 67: 695-700.

14. Amin AA, Marsh V, Noor AM, Ochola SA, Snow RW, 2003. The use of formal and informal curative services in the management of paediatric fevers in four districts in Kenya. Trop Med Int Health 8: 1143-1152.

15. Deressa W, Ali A, Enqusellassie F, 2003. Self-treatment of malaria in rural communities, Butajira, southern Ethiopia. Bull World Health Organ 81: 261-268.

16. Foster S, 1995. Treatment of malaria outside the formal health services. J Trop Med Hyg 98: 29-34.

17. McCombie SC, 1996. Treatment seeking for malaria: a review of recent research. Soc Sci Med 43: 933-945.

18. McCombie SC, 2002. Self-treatment for malaria: the evidence and methodological issues. Health Policy Plan 17: 333-344.

19. Redd SC, Kazembe PN, Luby SP, Nwanyanwu O, Hightower AW, Ziba C, Wirima JJ, Chitsulo L, Franco C, Olivar M, 1996. Clinical algorithm for treatment of Plasmodium falciparum malaria in children. Lancet 347: 223-227.

20. Weber MW, Mulholland EK, Jaffar S, Troedsson H, Gove S, Greenwood BM, 1997. Evaluation of an algorithm for the integrated management of childhood illness in an area with seasonal malaria in the Gambia. Bull World Health Organ 75 (Suppl 1): 25-32.

21. Koram K, Molyneux ME, 2007. When is "malaria" malaria? The different burdens of malaria infection, malaria disease, and malaria-like illnesses. Am J Trop Med Hyg 77 (Suppl 6): 1-5.

22. Pagnoni F, Convelbo N, Tiendrebeogo J, Cousens S, Esposito F, 1997. A community-based programme to provide prompt and adequate treatment of presumptive malaria in children. Trans $R$ Soc Trop Med Hyg 91: 512-517.

23. Dunyo SK, Afari EA, Koram KA, Ahorlu CK, Abubakar I, Nkrumah FK, 2000. Health centre versus home presumptive diagnosis of malaria in southern Ghana: implications for homebased care policy. Trans R Soc Trop Med Hyg 94: 285-288.

24. Greenwood BM, Bradley AK, Greenwood AM, Byass P, Jammeh K, Marsh K, Tulloch S, Oldfield FS, Hayes R, 1987. Mortality and morbidity from malaria among children in a rural area of The Gambia, West Africa. Trans R Soc Trop Med Hyg 81: 478-486.

25. Oshiname FO, Brieger WR, 1992. Primary care training for patent medicine vendors in rural Nigeria. Soc Sci Med 35: 1477-1484.

26. Kaona FA, Tuba M, 2003. Improving ability to identify malaria and correctly use chloroquine in children at household level in Nakonde District, Northern Province of Zambia. Malar J 2: 43.

27. Tawfik Y, Nsungwa-Sabitii J, Greer G, Owor J, Kesande R, PrysorJones S, 2006. Negotiating improved case management of 
childhood illness with formal and informal private practitioners in Uganda. Trop Med Int Health 11: 967-973.

28. World Health Organization, 2005. World Malaria Report. Geneva: World Health Organization.

29. Ministry of Health, 2003. Training Drug Retailers: A Programme Manager's Planning Guide. DOMC. Government printers, Nairobi.

30. Ministry of Health, 2001. National Malaria Strategy 2001-2010, An Introduction. Government printers, Nairobi.

31. Noor AM, Zurovac D, Hay SI, Ochola SA, Snow RW, 2003. Defining equity in physical access to clinical services using geographical information systems as part of malaria planning and monitoring in Kenya. Trop Med Int Health 8: 917-926.

32. Snow R, Noor A, Gikandi P, Tetteh G, Ochola S, 2003. Modelling the Anti-Malarial Drug Requirements for the Kenyan Government's Formal Health Sector Using Imperfect Data. Division of Malaria Control, Ministry of Health, Government of Kenya. Government printers, Nairobi.

33. Snow R, Ochola SA, Owino W, Gakuruh T, 2001. Strategic Development and Activity for Roll Back Malaria in Kenya 19982000. Nairobi: Ministry of Health with support from UNICEF.

34. Abuya TO, Mutemi W, Karisa B, Ochola SA, Fegan G, Marsh V, 2007. Use of over-the-counter malaria medicines in children and adults in three districts in Kenya: implications for private medicine retailer interventions. Malar J 6: 57.

35. Ministry of Health, 2005. Transition Plan for Implementation of Artemisinin-Based Combination Therapy (ACT) Malaria Treatment Policy in Kenya. DOMC. Government printers, Nairobi.

36. Amin AA, Zurovac D, Kangwana BB, Greenfield J, Otieno DN, Akhwale WS, Snow RW, 2007. The challenges of changing national malaria drug policy to artemisinin-based combinations in Kenya. Malar J 6: 72.

37. Madden JM, Quick JD, Ross-Degnan D, Kafle KK, 1997. Undercover careseekers: simulated clients in the study of health provider behavior in developing countries. Soc Sci Med 45: $1465-1482$.

38. Conteh L, Hanson K, 2003. Methods for studying private sector supply of public health products in developing countries: a conceptual framework and review. Soc Sci Med 57: 1147-1161.

39. Sophia Rabe-Hesketh AS, Pickles A, 2005. Maximum likelihood estimation of limited and discrete dependent variable models with nested random effects. J Econom 128: 301-323.

40. Greer GAA, Madueke L, Plowman B, Fapohunda B, Tawfik Y, Holmes R, Owor J, Gilpin U, Clarence C, Lennox B, 2004. Improving Management of Childhood Malaria in Nigeria and Uganda by Improving Practices of Patent Medicine Vendors.
Arlington, VA: BASICS II for the United States Agency for International Development.

41. Habicht JP, Victora CG, Vaughan JP, 1999. Evaluation designs for adequacy, plausibility and probability of public health programme performance and impact. Int J Epidemiol 28: 10-18.

42. Hayes RJ, Alexander ND, Bennett S, Cousens SN, 2000. Design and analysis issues in cluster-randomized trials of interventions against infectious diseases. Stat Methods Med Res 9: 95-116.

43. Victora CG, Habicht JP, Bryce J, 2004. Evidence-based public health: moving beyond randomized trials. Am J Public Health 94: 400-405.

44. Amin AA, Snow RW, 2005. Brands, costs and registration status of antimalarial drugs in the Kenyan retail sector. Malar J 4: 36.

45. Adikwu MU, 1996. Sales practices of patent medicine sellers in Nigeria. Health Policy Plan 11: 202-205.

46. Brieger WR, Osamor PE, Salami KK, Oladepo O, Otusanya SA, 2004. Interactions between patent medicine vendors and customers in urban and rural Nigeria. Health Policy Plan 19: 177-182.

47. Marquez L, 2001. Helping Health Care Providers Perform According to Standards. Bethesda, MD: US Agency for International Development.

48. Dzator J, Asafu-Adjaye J, 2004. A study of malaria care provider choice in Ghana. Health Policy 69: 389-401.

49. Goodman C, Kachur SP, Abdulla S, Mwageni E, Nyoni J, Schellenberg JA, Mills A, Bloland P, 2004. Retail supply of malaria-related drugs in rural Tanzania: risks and opportunities. Trop Med Int Health 9: 655-663.

50. Simmons R, Fajans P, Ghiron L, 2006. Scaling up health service deliver from pilot innovations to policies and programmes. Geneva: World Health Organization.

51. Goodman CA, Mutemi WM, Baya EK, Willetts A, Marsh V, 2006. The cost-effectiveness of improving malaria home management: shopkeeper training in rural Kenya. Health Policy Plan 21: $275-288$.

52. Sachs J, Malaney P, 2002. The economic and social burden of malaria. Nature 415: 680-685.

53. Bosman A, Mendis KN, 2007. A major transition in malaria treatment: the adoption and deployment of artemisinin-based combination therapies. Am J Trop Med Hyg 77: 193-197.

54. Goodman C, Kachur SP, Abdulla S, Bloland P, Mills A, 2007. Drug shop regulation and malaria treatment in Tanzania why do shops break the rules, and does it matter? Health Policy Plan 22: 393-403.

55. Charlwood D, 2004. The paradox of home management of malaria with artemisinin combinations. Trends Parasitol 20: 405-406. 